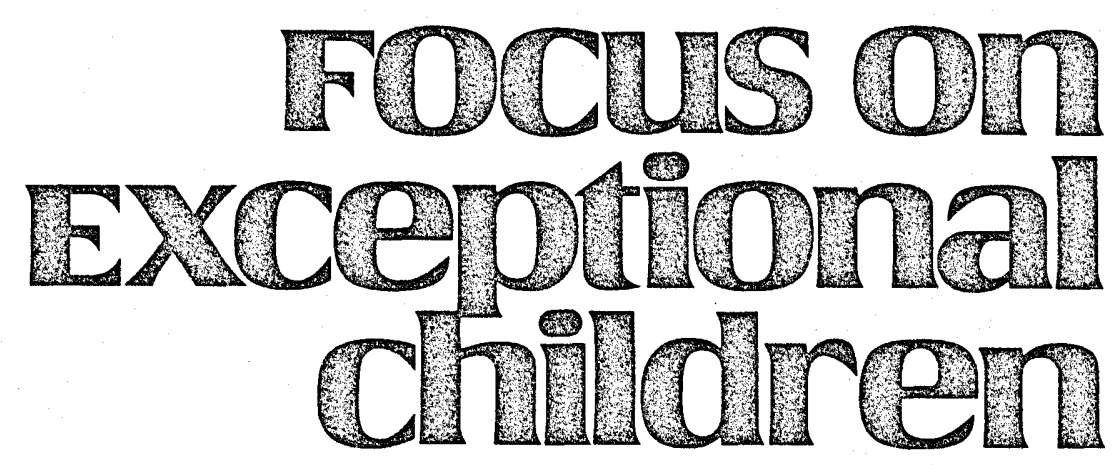

\title{
Instructional Planning for Dysfunctional Learners: Levels of Presentation
}

\author{
Floyd G. Hudson, Steven E. Colson, and Catherine Trefz Braxdale
}

Even though teachers have been taught instructional planning methods and most do some form of planning, few consistently plan instruction at the appropriate presentation levels for their assigned students. True, teachers write individualized education programs (IEPs) and lesson plans, but these are seldom interrelated in their stated goals and instructional objectives.

\footnotetext{
Until recently, instructional planning as a basis for special education programming has been something for which educators acknowledged the need, but something which was accomplished rarely. At the least, relatively little evidence is apparent of systematic instructional planning on behalf of exceptional children and youth. (Meyen, 1979, p. 139)
}

Instructional planning strategies employed by teachers should maximize the instruction time and, therefore, the students' performance over time. In addition, planning should make for efficient use of teacher time and be effective in meeting the instructional objectives developed by the teacher. The effectiveness of any instructional strategy should be based in its accommodation of individual differences and the needs of individual students with whom it is employed. The teacher's specificity, consistency, and systematic application of the instructional strategy are basic to its effectiveness as an appropriate instructional procedure.

Students often have difficulty acquiring mathematics, reading, spelling, and written expression skills when teachers fail to plan the instructional presentation at the child's level of learning. Teachers must determine the instructional readiness level for each skill to be taught. Often, teachers fail at this task, thereby prodding students to perform beyond their readiness level.

The authors are affiliated with the University of Kansas, where Floyd Hudson is Professor of Special Education, Coordinator of Personnel Preparation in Learning Disabilities, and Director of the Clinical Classroom for Learning Problems; Steven Colson is Associate Director of the Clinical Classroom for Learning Problems; and Catherine Braxdale is a Supervisory Teacher, Clinical Classroom for Learning Problems.

๑ Love Publishing Company, 1984. 
Three basic levels of readiness should be the concern of teachers in planning for children: (1) level of skill acquisition, (2) level of developmental readiness, and (3) level of presentation of skill (learning readiness level). Most teachers of dysfunctional learners are adept at basic skill assessment of students and with some degree of success can determine the level of developmental readiness for their assigned students. Most teachers, however, either do not assess or are unable to asses the presentation level of choice for the basic skills to be taught. For the most part, teachers tend to present all skills to all children at the same level of performance expectation and at the same level of presentation readiness.

An awareness of the student's level of learning for a specific task or skill is crucial to the student's learning efficiency. Consideration of the student's entry level cannot be done intuitively; it has to be done deliberately. The match between a student's level of learning and appropriate instructional procedures is not apparent to

\section{Focus on Exceptional children}

FOCUS ON EXCEPTIONAL CHILDREN (ISSN0015-5IIX) (USPS 203-360) is published monthly except June, July, and August as a service to teachers, special educators, curriculum specialists, administrators, and those concerned with the special education of exceptional children. This journal is abstracted and indexed in Exceptional Child Education Resources, and is also available in microform from Xerox University Microfilm, Ann Arbor, Michigan. Subscription rates, $\$ 18.00$ per year. Copyright $\odot$ 1984, Love Publishing Company. All rights reserved. Reproduction in whole or part without written permission is prohibited. Printed in the United States of America. Second class postage is paid at Denver, Colorado.

POSTMASTER: Send address changes to:

Love Publishing Company

Executive and Editorial Office

1777 South Bellaire Street

Denver, Colorado 80222

Telephone (303) 757-2579

EDITORIAL BOARD
Edward L. Meyen

University of Kansas

Glenn A. Vergason Georgia State University

Richard J. Whelan

University of Kansas Medical Center many teachers and, therefore, must receive objective consideration in the teaching strategy.

We propose a functional hierarchy designed for use with dysfunctional learners. It synthesizes work from several educational specialists.

The instructional strategy has been a major part of the clinical practicum experience for graduate-level trainees for more than 2 years and has been used daily in the Clinical Classroom for Learning Problems (CCLP) at the University of Kansas Medical Center, Kansas City, since inception of the program. This strategy has as its basis an awareness of the developmental stages of learning and an awareness of the importance of instructing students at their appropriate levels of readiness.

\section{DEVELOPMENTAL LEVELS OF LEARNING}

Many educators and educational measurements experts have structured cognitive objectives into hierarchies. These cognitive objectives deal with processes such as knowing, perceiving, recognizing, thinking, conceiving, judging, and reasoning. DeRuiter and Wansart (1983) have differentiated models of learning into functional hierarchies and developmental hierarchies. Functional hierarchies are those in which an

\section{STATEMENT OF OWNERSHIP MANAGEMENT AND CIRCULATION}

Date of Filing: September 30, 1984

Title of Publication: FOCUS ON EXCEPTIONAL CHILDREN

Frequency of Jssue: Monthly except June, July and August

Location of Known Office of Publication: 1777 S. Bellaire St., Denver, CO 80222

Location of Headquarters of Publisher: 1777 S. Bellaire St., Denver, CO 80222

Name and Address of Publisher, Editor, and Managing Editor: Stanley F. Love, 1777 S. Bellaire St., Denver, CO 80222

Owner: Stanley F. Love

Extent and Nature of Circulation:

Total No. Copies Printed

Paid Circulation

Sales through Dealers, etc.

Mail Subscriptions

Total Paid Circulation

Free Distribution

Total Distribution

Office Use and Left Over

Total

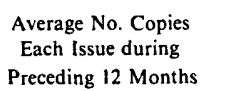

Single Issue

Nearest to

Preceding 12 Months Filing Date

4,044

3,500

0
3,353

3,353
3,353

3,353
250

3,603

441
4,044

0
3,162

3,162

3,162

150
3.312

3,312

188
3,500

I certify that the statements made by me above are correct and complete.

(Signed) Stanley F. Love, Publisher 
individual may use any level of strategy that has been developed, even though the highest level attained may be the most appropriate level of strategy from which to respond. Developmental hierarchies are those in which individuals do not return to earlier stages once they have developed further. Four of the best known hierarchies of cognitive objectives were developed by Bloom, Piaget, Bruner, and Gangne'.

\section{Bloom's Taxonomy}

Bloom, Englehart, Furst, Hill, and Krathwohl (1956), cognitive behaviorists, identified six major areas within which cognitive objectives may be classified:

1.00-Knowledge: The ability to remember-recall or recognize-ideas, facts, etc., in a situation in which certain cues, signals, and clues are given to bring out effectively whatever knowledge has been stored.

2.00-Comprehension: The ability to receive what is being communicated and make use of it without necessarily relating it to other material or seeing its implications.

3.00-Application: The ability to use abstraction, rules, principles, ideas, and methods in particular and concrete situations.

4.00-Analysis: The ability to break down some communication into its constituent elements or parts.

5.00-Synthesis: The ability to work with pieces, parts, elements, etc., and combine or put them together in some way to form a whole or constitute a new pattern or structure.

6.00-Evaluation: The ability to make quantitative and qualitative judgments about the extent to which materials and methods satisfy criteria. According to the builders of the taxonomy, this is the highest level of cognitive activity.

\section{Piaget's Theory}

Probably the best known developmental hierarchy is that of Jean Piaget. Piaget (1951) saw intellectual devel- opment as having four main stages: sensorimotor, preoperational (which is subdivided into preoperational and intuitive), concrete operational, and formal operations.

In Piaget's theory of development of knowledge, all individuals are regarded as developing through these four different stages in the evolution of thought processes. In each successive stage, thinking increases in complexity. These are not quantitative increases but, rather, represent completely different thinking strategies. Once an individual's thought structures have been restructured in terms of the next higher level, that level becomes the basis of thinking. Piaget stressed, to much ensuing criticism, that these levels develop as age increases and are always developed in the same sequence.

\section{Bruner's Theory}

Jerome Bruner (1966) spent considerable time examining the development of cognitive functions. The following six points are the foundation for his theory:

1. Intellectual growth is characterized by increasing independence of a response from a stimulus.

2. Growth depends upon the development of an internal storage and information processing system that can describe reality.

3. Intellectual development involves an increasing capacity to say to oneself and others, by word or symbols, what one has done and what one will do.

4. Systematic interactions between a tutor and a learner are necessary for cognitive development.

5. Language is the key to cognitive development.

6. Cognitive growth is marked by the increasing ability to deal with several alternatives simultaneously, to perform concurrent activities, and to allocate attention sequentially to various situations.

Bruner described three stages of growth in the ways that children come to represent the world:

1. Enactive: Action is the way the child understands his/her environment. This is comparable to Piaget's concrete stage.

2. Iconic: Information is carried by imagery. Piaget's description of the early stages of preoperational thought overlap with Bruner's iconic stage. 
3. Symbolic: Nonthinking action and perceptional understanding give way to symbolic systems. This compares to Piaget's concrete and formal operational stages.

\section{Gangne's Conditions of Learning}

Gangne' (1970) described eight varieties of learning that can be distinguished from each other:

1. Signal Learning: The individual learns to make a general, diffuse response to a signal.

2. Stimulus-Response Learning: The learner requires a precise response to a discriminated stimulus.

3. Chaining: What is acquired is a chain of two or more stimulus-response connections.

4: Verbal Associations: Verbal association is the learning of chains that are verbal.

5. Discriminating Learning: The individual learns to make different identifying responses to as many different stimuli, which may resemble each other in physical appearance to a greater or lesser degree.

6. Concept Learning: The learner acquires a capability of making a common response to a class of stimuli that may differ from each other widely in physical appearance.

7. Rule Learning: A rule is a chain of two or more concepts.

8. Problem Solving: Problem solving is a kind of learning that requires the internal events usually called thinking. Two or more previously acquired rules are somehow combined to produce a new capability that can be shown to depend on a higher order rule.

The theories of Bloom, Piaget, Bruner, and Gangne' represent a framework that allows teachers to begin to put learning into perspective. These theoretical constructs form the foundation for understanding the learning process in normally developing children but in themselves cannot give educators a specific look at dysfunctional learners. That is why we have to go a step further and look at hierarchies developed specifically to examine the learning processes of these dysfunctional learners.

\section{Hierarchical Models for Dysfunctional Learners}

Several researchers in the field of learning problems have constructed hierarchies for use with dysfunctional learners. Kephart (1971) proposed a theory of development similar to Piaget's, in which higher levels of thinking develop from prerequisite motor and perceptual stages. Kass (1977) presented five age-related developmental functions that could explain the reason for a child's failure to perform. Kirk, McCarthy, and Kirk (1968) used a functional hierarchy in developing the Illinois Test of Psycholinguistic Abilities. Johnson and Myklebust (1967) developed a system of five behavioral classifications including sensation, perception, imagery, symbolization, and conceptualization. Many of these hierarchies are not age-related, and individuals can continue to experience difficulty at lower levels of the hierarchies even though they have progressed beyond that in the hierarchical sequence.

DeRuiter and Wansart (1983) developed five levels of responses with corresponding learning processes and principles of teaching in relation to learning disabled persons:

\section{Response Level}

1. Awareness

2. Differentiation

3. Labeling

4. Understanding

5. Habit

\section{Learning Process}
Attention
Perception
Memory
Cognition
Encoding

After a review of past research, Smith and Robinson (in press) developed a hierarchy showing stages of learning that lead to ultimate mastery through continual increases in a skill's frequency. The levels and the corresponding aims are listed below.
Level of Learning

1. Entry

2. Acquisition (initial and advanced)

3. Proficiency

4. Maintenance

5. Generalization

6. Adoption
Aim

(no aim)

Accuracy (90-100\%)

Fluency (desired rate)

Retention

Expansion

Extension 
Haring and Eaton (1978) offered a four-stage hierarchy that, when used properly, increased the efficiency of the teaching/learning act.

\section{Level}

1. Acquisition

2. Fluency or proficiency

3. Generalization

4. Adaption

Haring and Eaton encourage research into the specific teaching procedures that can facilitate each stage of the learning hierarchy.

These hierarchical models involving dysfunctional learners give teachers a more specific framework for structuring learning experiences. Children, however, do not learn from theoretical models but, rather, from well planned applications of these theories.

\section{APPLICATION OF PRESENTATION LEVELS}

Since the enactment of Public Law 94-142, the focus of special education has been on development and implementation of the individualized education program for all special students being served in our schools. It frequently seems that too much attention is given to the IEP, whether manually prepared or computer generated, at the expense of weekly and daily planning for attainment of long-range goals and short-term objectives delineated by the IEP. The IEP is a framework that links student needs to the education delivered, but it does not specify the planning process to be followed (Hudson \& Graham, 1978). Teachers would do well to concentrate more on the control of the mathemagenic behaviors, those behaviors that give birth to learning, by matching nominal stimuli, that put forth by the teacher, to effective stimuli, that actually processed by the student (Gage \& Berliner, 1979).

The presentation levels (Figure 1) proposed here are not to be viewed as yet another listing of how students

\section{LONG-RANGE GOAL}

\section{SHORT-TERM OBJECTIVES}

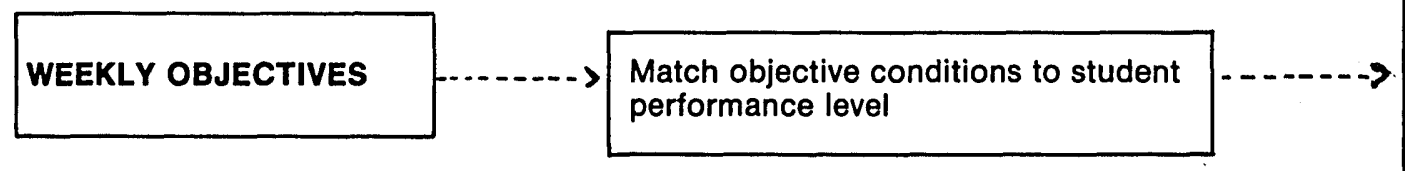

Generalization

Maintenance Application

Recall

Recognition

Awareness

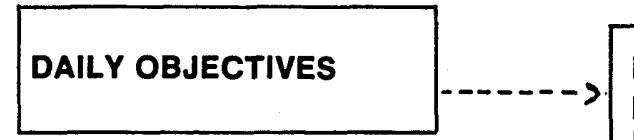

Match daily objectives to student performance levels based on results of probes at the presentation levels

\section{LEVELS}

Generalization

Maintenance

Application

Recall

Recognition

Awareness

FIGURE 1

Diagramatic Presentation of the Instructional Strategy: Levels of Presentation 
learn or process information but, rather, as levels of presentation designed as an aid to teachers in developing instructional programs that correlate nominal and effective stimuli for dysfunctional learners. Special classrooms, resource rooms, or small remedial groups are rarely composed of students who are able to grasp an idea, concept, or task in the same way or at the same rate. Through the use of these presentation levels, the teacher can note the level of a particular student at the time of entry to instruction and follow that student on a daily basis by continually assessing his/her progress from one level to the next. These levels also aid the teacher in achieving long-range goals and short-term objectives through a systematic approach to weekly and daily planning.

The six presentation levels in this model are:(1)awareness, (2) recognition, (3) recall, (4) application, (5) maintenance, and (6) generalization. These levels are presented in Figure 2 in ascending order. The presentation levels, however, are not isolated. They are interactive and should be considered neither as individual entities nor as developmentally hierarchical, though instruction becomes more complex at each successive level. As instruction flows from one level to the next, skills are integrated. As the more complex level emerges, the preceding level fades.

\section{Awareness}

No knowledge of an item, concept, task, or material is present at the awareness level. Depending on the age of the student and appropriateness of the task, teaching at this level can be in concrete, semi-concrete, or abstract forms. The awareness level gives the student the opportunity to know that an item exists. A student must be aware of an item in order to learn it. Once the student is aware of an item, he/she is prepared and will begin to recognize and include that item in his/her environment.

A pre-school student at the awareness level may be unable to differentiate numerals from letters and use both interchangeably in the context of writing. At a more advanced grade level, say fourth grade, a student may not be aware that the subtraction facts he/she has mastered in the classroom can be applied to generalizing that skill in real life situations (e.g., checking to make sure he/she has received the correct change after making a purchase).

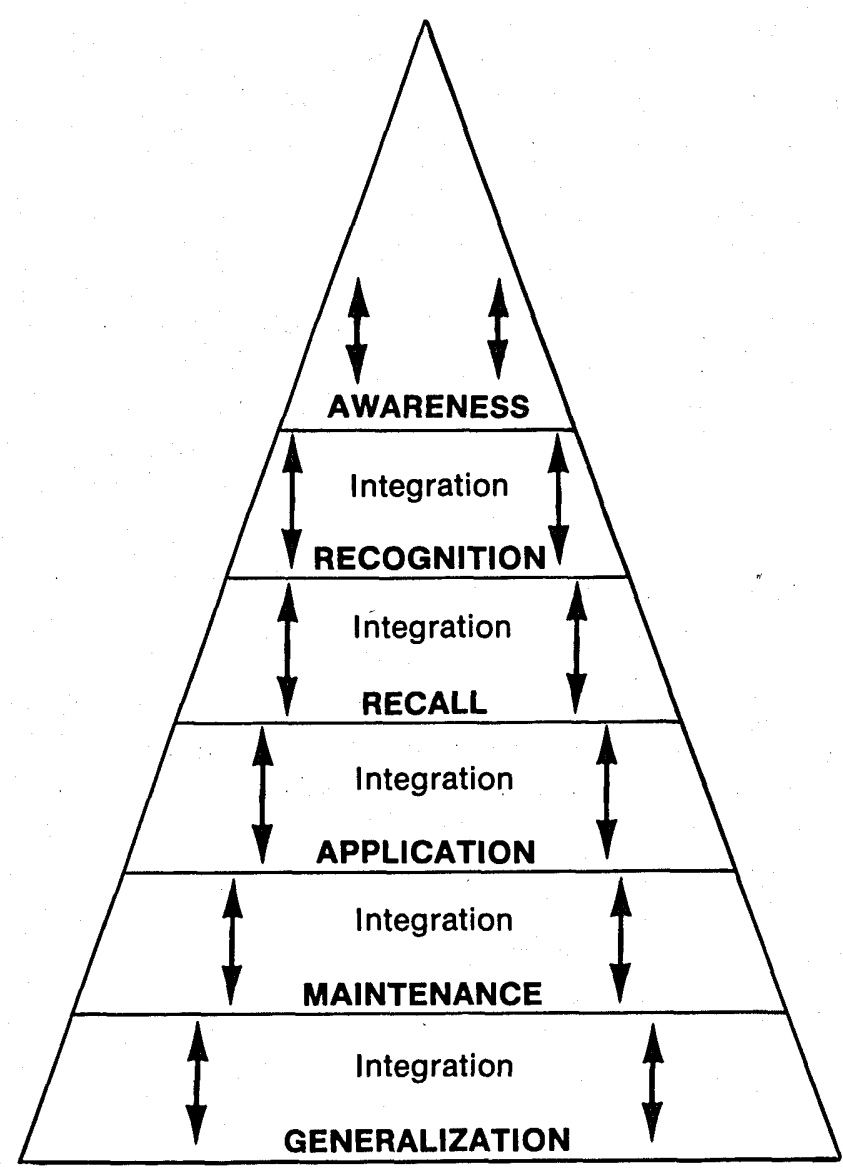

FIGURE 2

Levels of Presentation

\section{Recognition}

At the recognition level a specific item can be discriminated from similar items. The student is able to focus attention away from distractors and onto the specific target stimulus. This level, as the awareness level, can be demonstrated, practiced, and evaluated at the concrete, semi-concrete, or abstract levels, depending on the student's existing knowledge base and the appropriateness of the task.

At the recognition level the student receives opportunities to become proficient at recognizing and discriminating an item from similar stimuli in the environment. Through repeated recognition of the item, the student becomes familiar with how, when, and why that item is used, in preparation for using the item independently. 
Moving a student from the awareness level of a task to performance of that task would be difficult without some prior experience in recognizing, matching, or modeling.

Students working at the recognition level are able to discriminate a specific stimulus from similar stimuli. A teacher may present a lesson in concrete form for the preschool or primary student, using various geometrical shapes or other concrete objects from which the student is to select a specific shape or object. At the abstract level an intermediate level student may be asked to underline all the verbs or some other designated part of speech in a passage.

\section{Recall}

Students at the recall level are able to generate ideas or perform tasks in an independent manner with no clues from the environment. This level can be demonstrated in either oral or written form. At this level the student relies on his/her own inner resources for retrieving information.

The recall level offers students the opportunity to generate responses repeatedly for the purpose of learning, even overlearning, in rote manner. This, according to Gage and Berliner (1979), is an effective way of controlling mathemagenic behavior. When rote responses are achieved, the student is prepared to apply newly acquired knowledge in a meaningful way without having to completely rethink each step. The responses can be in oral or written form.

As in all levels, the recall level is not specific to any age group. For example, a kindergarten student may respond at the recall level in reciting the alphabet, while an intermediate student may use the recall level in responding to timed multiplication fact tests.

Students at this level are preparing to apply rote information in a more meaningful setting. At the point when a student begins to grasp a concept, the teacher begins to introduce that student to, and integrate him/her into, the next level. At the same time, the teacher remembers to draw from the recognition level those aspects of the concept that were most difficult for the student.

\section{Application}

Rote information is applied in a meaningful or simulated real life situation at the application level. This is the level at which students usually appear to meet mastery and demonstrate proficiency in the classroom.

The application level provides the student with an opportunity to see, in a direct instructional situation, how the splinter skills that he/she has learned in a rote manner can serve him/her in real life. This is particularly important to the dysfunctional learner who often does not see the whole of a skill, but only the parts. Thus, presentation is diverse at the application level, giving the student as many opportunities as possible to see related skills as a part of a meaningful whole.

Students operating at the application level are beginning to use some self-generated strategies and ideas for applying the rote information they have learned to simulated real life situations presented in the classroom. A student may need to be made aware that the skills do apply in the larger context of his/her life. For example, a kindergarten student who has learned to respond at the recall level for all letter sounds, and is now ready to begin applying those sounds to blends and words, must first be made aware that these individual sounds do indeed make up the words in books. Another example might be an intermediate student who begins to apply the rote learning of multiplication facts to word problems.

Many dysfunctional students have great difficulty applying skills to real life. Therefore, the teacher must plan for application of a skill in many diverse ways, looking toward the next level, maintenance, as a means of continuous monitoring.

\section{Maintenance}

At the maintenance level the teacher periodically spotchecks skills to ensure that they are being held constant in preparation for generalization to other areas. Once a skill has been mastered, it is often forgotten. To counteract this, the maintenance level affords an opportunity for continued application of newly learned skills. When the maintenance level is viewed as an integral part of learning, it can and should be acknowledged on the IEP and incorporated into daily or weekly planning.

During work at this level, the teacher periodically asks the student to demonstrate, in an informal manner, the newly learned skill. The kindergarten student may be rated as to the number of words pronounced correctly during oral reading period; the intermediate student who 
has difficulty telling time may be asked to tell the teacher the time, and the accuracy of the response could be charted. If the student seems to be losing accuracy in applying a skill during the maintenance level, the teacher re-teaches that skill through direct instruction.

\section{Generalization}

The student who is working at the generalization level freely applies learned skills to varying areas and situations (both in the classroom and real life) that differ from the environment in which the skill was first learned. The skill becomes a point of reference upon which expansion can occur.

At the generalization level the student uses skills, concepts, ideas, or materials that were previously associated with one environment in varied or different environments. Once a student has mastered a task at this level, he/she will be less likely to lose it because of a lack in retrieval skills.

Learning becomes automatic. The skills learned in one environment are subsumed into the student's everyday living experience. A primary student who reads street signs, billboards, or a cartoon has generalized the skill of reading to everyday life. An intermediate student's recognition of receiving incorrect change at the time of a purchase indicates generalization of the skills of subtraction and change making.

\section{IMPLEMENTATION OF PRESENTATION LEVELS}

As the teacher begins to implement these presentation levels in planning, three initial questions must be answered:

1. How is the presentation level of each student determined?

2. How is the information evaluated?

3. What are some appropriate tasks for teaching at each level?

Determination of a student's present level of performance is accomplished through a series of probes. Probing begins at a level chosen by the teacher, based on how the short-term objective is written and the student's age and/or grade placement. If the student fails to respond accurately at the initial level of probing, the teacher moves to the next lower level and begins the probing process again. Probing begins at the highest point feasible and proceeds downward. The instruction, on the other hand, is initiated at the basal point of performance and proceeds upward.

For the skill of multiplication, specific probes at each level of presentation are:

1. Generalization: Interview questions can be asked to determine if the student uses multiplication in everyday life. ("How many people are on your paper route?" "What amount does each customer pay per month?" "How much do you collect all together?")

2. Maintenance: The purpose of this level is to sustain performance at the application level in preparation for generalizing that skill to other settings. Therefore, probing at this level is accomplished by presenting materials that require the student to periodically perform the skills at the application level, in preparation for generalizing the skills to other areas.

3. Application: Probes at this level would likely take the form of word problems for the student to set up and compute correctly. If the student performs between $70 \%$ and $90 \%$ on repeated trials, one can assume that application is the appropriate teaching level for this student. If the score is below $70 \%$, the appropriate level of instruction is recall. If the score is above $90 \%$, the student can be moved on to the maintenance level.

4. Recall: Probing this level involves either oral stimuli from the teacher and verbal responses from the student, or timed or untimed written tests. If the student performs between $70 \%$ and $90 \%$ on at least four consecutive probes, the teaching level is established at recall. If the score is below $70 \%$, the student is moved to the recognition level; if the score is above $90 \%$, the teacher can begin to integrate the application level.

5. Recognition: To probe at this level, the student could be presented with a multiplication problem and three choices of answers for each problem. The student may either underline, circle, or point to the correct answer. Performance between $70 \%$ and $90 \%$ on at least four probes suggests that this is the appropriate teaching level for this student. 
A score below $70 \%$ would not necessarily indicate performance at the awareness level, but it would necessitate probing at a lower level of recognition. In this case the student should move to recognition of the correct answer with two obviously diverse choices. An initial score above $90 \%$ on four consecutive probes would indicate that the student is ready to begin integration to the recall level.

6. Awareness: Probing at the awareness level involves interviewing the student to make him/her aware of an item. In the case of multiplication, the teacher would explain that $3 \times 4$ was the same as $4+4+4$; thus making the student aware that multiplication is an expansion of addition. After the student can explain this idea, he/she is ready to begin working at a very basic recognition level. For example, the teacher may assign multiplication problems with answers displayed; the teacher would ask the student to point to, underline, or circle a specific problem.

\section{EVALUATION OF STUDENT PERFORMANCE}

The process of evaluating a student's performance is crucial to the success of any instructional program. Graphs provide the teacher a visual display of the student's performance that is easily interpreted to colleagues and supervisors. Graphs also serve as visual evidence of the teacher's efforts to address and monitor progress of a student toward achievement of short-term objectives and long-range goals. As the teacher plans for future instruction, trends indicated on the graph can aid in determining whether instruction should proceed to the next level, remain static, or be simplified. Graphing styles should be based on their effectiveness and appropriateness in interpreting evaluation data.

The graph presented here (see Figure 3 ) is offered as an example of a student's performance on three different presentation level probes spanning a 3-day period. By examining the graph, several facts can be observed: (1) The highest presentation level probed was application,

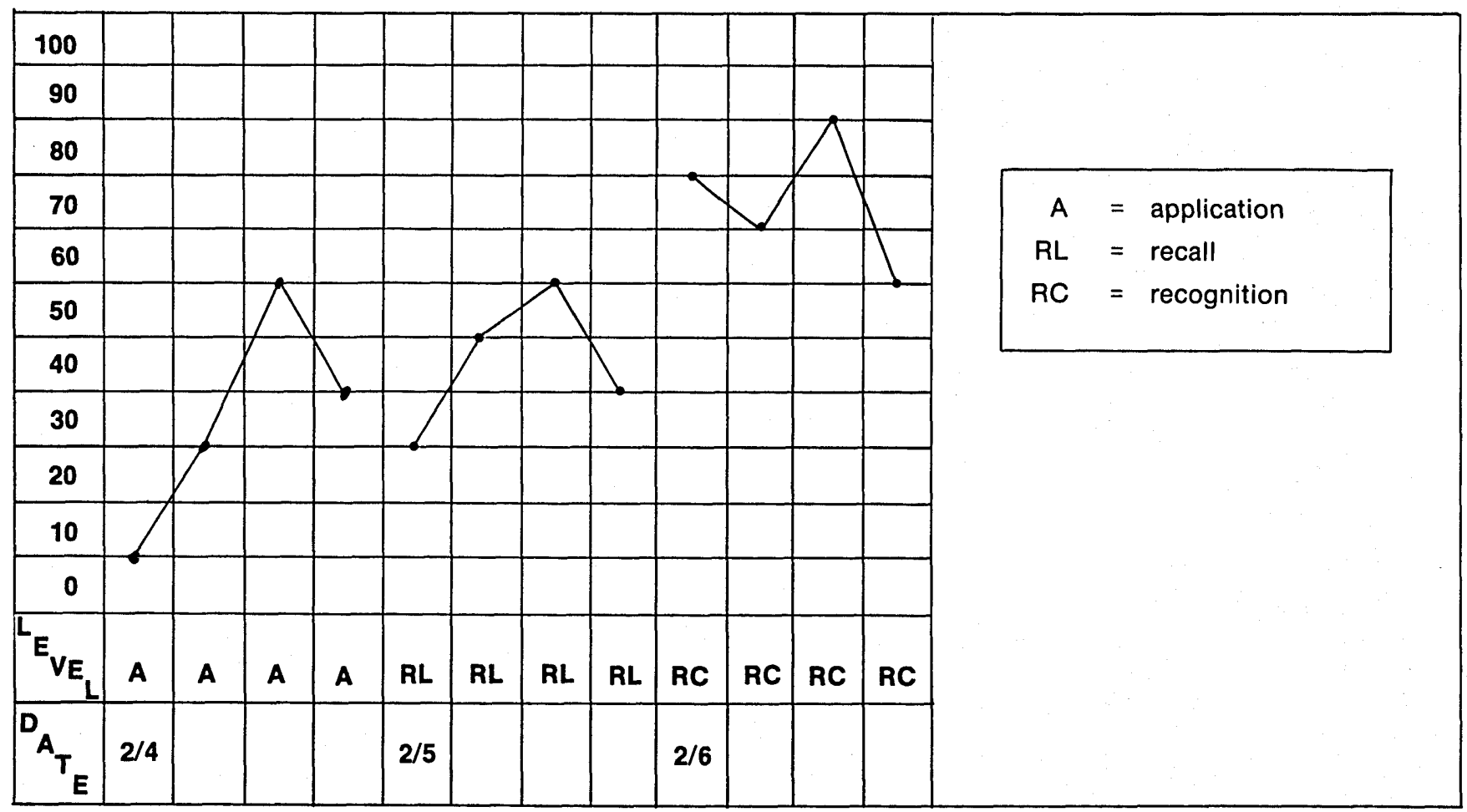

FIGURE 3

Graph of a Student's Performance During Three Presentation Level Probes 
Long-Range Goal:

Short-Term Objective:

Weekly Goal:
Improve math skills

Given 10 word problems requiring the use of multiplication, student will set up and compute the problems with $100 \%$ accuracy on 3 of 4 weekly trials.

Student will recognize the correct response for the multiplication facts of 3. (Graph on Friday)

\section{DAILY PLANS:}

Monday: Length of lesson: 15 to 20 minutes.

- Discuss what we are going to accomplish this week.

- Present the student with each multiplication problem for $3(3 \times 0=0$ to $3 \times 12=36)$ on $4^{\prime \prime} \times 6^{\prime \prime}$ index cards.

- Ask the student to say each problem aloud with the teacher.

- Ask the student to say each problem aloud without the teacher.

- Ask the student to point to specific problems as the teacher mentions them.

- Let the student ask the teacher to point to specific problems, and have student indicate if the teacher was correct.

- Summarize what work was done that day, and outline work for tomorrow.

Tuesday: Length of lesson: 15-20 minutes

- Discuss what was done Monday.

- Show student cards duplicate to the ones used Monday.

- Teacher and student say each problem as they go through the cards.

- Have student say each problem without the teacher.

- Have student cut the answer away from the problem on one set of cards.

- Have student match the parts of problems to the whole cards, saying the problem while doing so.

- Summarize what work was done that day, and outline work for tomorrow.

Wednesday: Length of lesson: 15 to 20 minutes

- Discuss what was done Tuesday.

- Show student the whole cards from Tuesday, and have student say each problem aloud without the teacher.

- Put the whole problem cards aside.

- Have student match the problems to answers, using the cards that are cut.

- Repeat this procedure.

- Summarize what work was done that day, and outline work for tomorrow.

Thursday: Length of lesson: 15 to 20 minutes

- Discuss what was done Wednesday.

- Have student match the problems to answers, using the cards cut in half.

- Give student a sheet of problems displaying all the multiplication facts of 3 . Each problem has two choices.

- Have student underline the correct answer (repeat with another sheet).

- Have student use key to self-evaluate the second performance.

- Summarize what work was done that day, and outline work for tomorrow.

Friday: Length of lesson: 15 to 20 minutes

- Discuss what was done Thursday.

- Have student match the problems with answers, using the cards cut in half.

- Give student a sheet of problems displaying all the multiplication facts of 3 . Each problem has three choices.

- Have student underline the correct answer (with teacher guidance).

- Repeat with another sheet (without teacher guidance).

- Have student use key to self-evaluate second performance, and graph.

- Summarize what work has been done that week, and explain that on Monday the student will begin in the same manner to learn the "fours" and will begin to use the flash cards and timed tests to check "threes."

\section{FIGURE 4}




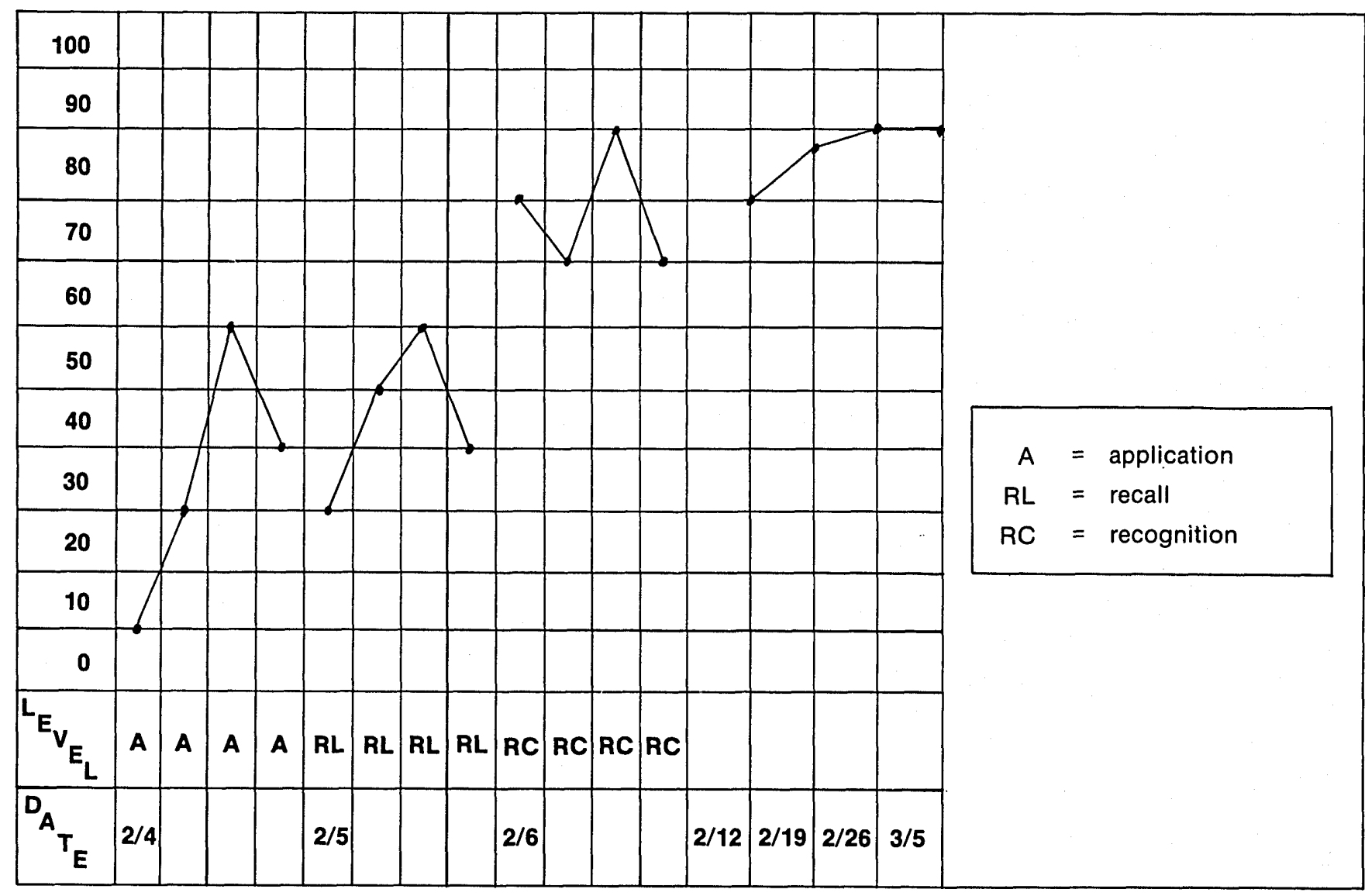

FIGURE 5

Graph of a Student's Performance over a 4-week Period Using the Presentation Levels

and probing moved downward from that point, (2) the application level probe yielded scores ranging from $10 \%$ to $60 \%$, too low for establishing instruction at the recall level, (4) the recognition level probe yielded scores ranging from $70 \%$ to $90 \%$, indicating that this student is operating at the recognition level, and (5) instruction will begin at the recognition level and proceed toward integration with the recall level. The suggested Reading List at the end of this article can be consulted for additional graphing formats.

Figures 4 and 5 are offered as examples of planning and evaluation of a student's performance using the presentation levels. Since the weekly goal focuses on the recognition level, each daily plan will incorporate activities requiring the student to recognize specific multiplication items when presented with distractors. This stu- dent was evaluated each Friday for 4 consecutive weeks at the recognition level, with scores ranging from $80 \%$ to $90 \%$. These scores indicate that probing should be resumed at the recall level. Probing prior to planning, planning for instruction, and evaluating performance following instruction lead to probing at the next highest level.

\section{SUMMARY}

Since the goal of instruction for dysfunctional learners is to provide for their individual differences and unique needs, teachers must develop and implement efficient and effective planning methods. To meet the learning needs of students, teachers must be aware of each student's level of 


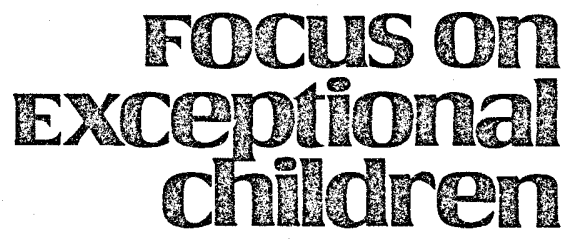

learning readiness for obtaining skill proficiency. An awareness of the student's learning readiness will dictate the presentation level appropriate for instruction. The instructional strategy presented here delineates the various stages of functional learning - awareness, recognition, recall, application, maintenance, and generalization. The teacher's implementation of this hierarchy of learning facilitates the student's acquisition of basic skills.

Haring and Eaton (1978) have stated "There is a compelling need to conduct research into the specific teaching procedure which can facilitate each stage of the learning hierarchy. Verifying the effectiveness of various instructional procedures as they relate to learner progress through stages of learning may illuminate certain inconsistencies in previously conducted research in learning" (p. 35). Knowledge of instructional strategies and supportive research data, however, are not enough to guarantee the implementation of an appropriate teaching-learning match. Teachers must be provided instruction and participate in staff development focusing on the implementation of levels of presentation, and they must be reinforced for its use. Only then can programs for dysfunctional learners be individualized and successful.

\section{REFERENCES}

Bloom, B.S., Englehart, M.B., Furst, E.J., Hill, W.H., \& Krathwohl, D.R. (1956). Taxonomy of educational objectives. New York: Longmans Green.

Bruner, J.S. (1966). Toward a theory of instruction. New York: Belknap Press/Harvard University Press.

DeRuiter, J., \& Wansart, W. (1983). Psychology of learning disabilities: Applications and educational practice. Rockville, MD: Aspen Systems Corp.

Gage, N., \& Berliner, D. (1979). Educational psychology. Chicago: Rand McNally.

Gangne', R.M. (1970). The conditions of learning. New York: Holt, Rinehart \& Winston.

Haring, N.G., \& Eaton, M.D. (1978). Systematic instructional procedures: An instructional hierarchy. In N.G. Haring, T.C. Lovitt, M.D. Eaton, \& C.L. Hansen (Eds.), The fourth R: Research in the classroom (pp. 25-40). Columbus, OH: Merrill Publishing.

Hudson, F., \& Graham, S. (1978). An approach to operationalizing the IEP. Learning Disability Quarterly, 1(1), 13-32.

Johnson, D., \& Myklebust, H. (1967). Learning disabilities: Educational principles and practices. New York: Grune \& Stratton.

Kass, C.E. (1977). Identification of learning disability. Journal of Learning Disabilities, 10, 425-432.

Kephart, N. (1971). The slow learner in the classroom (2nd ed.). Columbus, $\mathrm{OH}$ : Charles E. Merrill.

Kirk, S., McCarthy, J., \& Kirk, W. (1968). Illinois test of psycholinguistic abilities (rev. ed.). Urbana: University of Illinois Press.

Meyen, E. (1979). Instructional planning. In E.L. Meyen, G.A. Vergason, \& R.J. Whelan. Instructional planning for exceptional children: Essays from Focus on Exceptional Children (pp. 139-140) Denver: Love Publishing.
Piaget, J. (1951). The origins of intelligence in children. (Margaret Cook, Trans.). New York: International Universities Press.

Smith, D.D., \& Robinson, S. (in press). Educating the learning disabled. In B. Blatt \& R.J. Morris (Eds.), Perspectives in special education. Glenview, IL: Scott, Foresman.

\section{SUGGESTED READING LIST}

Adelman, H.S., \& Taylor, L. (1983). Learning disabilities in perspective. Glenview, IL: Scott, Foresman.

Bloom, B.S., Englehart, M.D., Furst, E.J., Hill, W., \& Krathwohl, D.R. (1956). Taxonomy of educational objectives: Handbook I: Cognitive domain. New York: McKay.

Bruner, J.S. (1966). Toward a theory of instruction. Cambridge, MA: Belknap Press/Harvard University Press.

Cawley, J.F., Fitzmaurice, A.M., Goodstein, H.A., Lapore, A.V., Sedlak, R., \& Althaus, V. (1976). Project math. Tulsa, OK: Education Development Corp.

Gangne', R.M. (Ed.) (1967). Learning and individual differences. New York: Macmillan.

Gallagher, P.A. (1979). Teaching students with behavior disorders: Techniques for classroom instruction. Denver: Love Publishing.

Haring, N.G., \& Bateman, B. (1977). Teaching the learning disabled child. Englewood Cliff, NJ: Prentice-Hall.

Harris, A.J., \& Sipay, E.T. (1980). How to increase reading ability: $A$ guide to developmental and remedial methods (7th ed.). New York: Longman. .

Hudson, F., \& Graham, S. (1978). An approach to operationalizing the IEP. Learning Disability Quarterly, 1(1), 13-32.

Idol-Maestas, L. (1983). Special educators' consultation handbook. Rockville, MD: Aspen Systems Corp.

Joyce, B., \& Weil, M. (1972). Models of teuching. New York: PrenticeHall.

Kibler, R.J., Baker, L.L., \& Miles, D.J. (1970). Behavior objectives and instruction. Boston: Allyn \& Bacon.

Kohlberg, L., \& Mayer, R. (1972). Development as the aim of education. Harvard Educational Review, 42, 449-496.

Krathwohl, D.R., Bloom, B.S., \& Masia, B.B. (1964). Taxonomy of educational objectives: Handbook 2: Affective domain. New York: McKay.

Mercer, C., \& Mercer, A. (1981). Teaching students with learning problems. Columbus, $\mathrm{OH}$ : Charles E. Merrill.

Popham, W.J. (1975). Educational evaluation. Englewood Cliffs, NJ: Prentice-Hall.

Popham, W.J., Eisner, E.W., Sullivan, H.J., \& Tyler, L.L. (1969). Instructional objectives. American Educational Research Association, 3. Chicago: Rand McNally.

Poplin, M. (1979). The science of curriculum development applied to special education and the IEP. Focus on Exceptional Children, 12(3), 1-16.

Radabaugh, M., \& Yukish, J. (1982), Curriculum and methods for the mildly handicapped. Boston: Allyn \& Bacon.

Rossi, P.H., Freeman, H.E., \& Wright, S.R. (1979). Evaluation: $A$ systematic approach. Beverly Hills, CA: Sage Publications.

Sabatino, D.A., Schmidt, C.R., \& Miller, T.L. (1981). Learning disabilities: Systemizing teaching and service delivery. Rockville, MD: Aspen Systems Corp.

Stephens, T. (1976). Directive teaching of children with learning and behavioral handicaps. Columbus, $\mathrm{OH}$ : Charles E. Merrill.

Stephens, T., Hartman, A., \& Lucas, V. (1978). Teaching children basic skills. Columbus, OH: Charles E. Merrill.

Wiederholt, J.L., Hammill, D.D., \& Brown, V. (1983). The resource teacher: A guide to effective practice (2nd ed.). Austin, TX: Pro-Ed Publishing. 